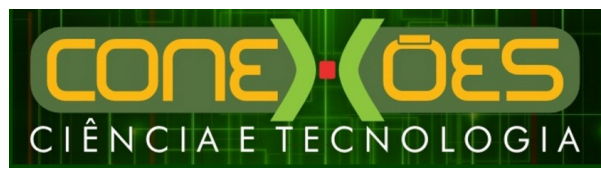

\title{
CAMINHOS PERCORRIDOS PELA GEOLINGUÍSTICA NOS SERTÕES CEARENSES: PESQUISA DE CAMPO
}

\author{
Fabiana dos Santos Lima ${ }^{1}$, Paula Perin dos Santos $^{2}$, Maria do Socorro Silva de Aragão ${ }^{3}$ \\ ${ }^{1}$ Instituto Federal de Educação, Ciência e Tecnologia do Ceará - IFCE, \\ ${ }^{2}$ Secretaria Municipal de Educação de Juazeiro do Norte-CE; Universidade Regional do Cariri (URCA), \\ ${ }^{3}$ Universidade Federal do Ceará (UFC) \\ <flimasantos@gmail.com>
}

DOI: $10.21439 /$ conexoes.v12i2.1454

\begin{abstract}
Resumo. Enquanto se encontra no conforto do seu lar, rodeada de inúmeros textos científicos que lhe orientam acerca dos passos metodológicos que uma pesquisa geolinguística deve seguir, tudo parece simples, prático e rápido. No entanto, quando toda a metodologia planejada vai a campo, a situação se configura completamente diferente e os desafios que se apresentam devem ser superados, ou então, todo o trabalho projetado se desmorona. É com o intuito de relatar os desafios enfrentados pela pesquisadora em questão durante a pesquisa de campo do Atlas Linguístico dos Sertões Cearenses (ALSCe) que produzimos este trabalho. O ALSCe será um atlas linguístico que documentará o léxico e a morfossintaxe do falar cearense na mesorregião geograficamente definida como os Sertões Cearenses. Para que esse atlas se concretize é preciso passar por várias etapas, desde a escolha da localidade até a produção das cartas linguísticas. Com tudo isso, faz-se necessário que, após a definição das variáveis extralinguísticas (local, sexo, idade e escolaridade), realizemos a pesquisa de campo propriamente dita. É neste aspecto que discorremos ao longo deste trabalho para servir de orientação para futuros pesquisadores geolinguistas que, assim como nós, estarão dispostos a deixar o conforto de seus lares e se aventurarem pelo universo extraordinário da língua falada no cotidiano. Para alicerçar cientificamente nosso trabalho, recorremos a Caruso (1998), Brandão (2005), Alencar et al. (2016), Ferreira (2016).
\end{abstract}

Palavras-chaves: Dialetologia. Metodologia. Geolinguística. Ceará.

\begin{abstract}
While in the comfort of your home, surrounded by numerous scientific texts that guide you about the methodological steps that a geolinguistic research must follow, everything seems simple, practical and fast. However, when all of the planned methodology goes into the field, the situation is completely different and the challenges presented must be overcome, or all the projected work collapses. It is with the intention of reporting the challenges faced by the researcher in question during the field research of the Linguistic Atlas of the Sertões Cearenses (ALSCe) that produced this work. The ALSCe will be a linguistic atlas that will document the lexicon and the morphosyntax of the Ceará language in the mesoregion geographically defined as the Sertões Cearenses. For this atlas to take place it is necessary to go through several stages, from the choice of locality to the production of the linguistic charts. With all this, it is necessary that, after defining the extralinguistic variables (location, sex, age and schooling), we perform the field research itself. It is in this aspect that we discuss throughout this work to serve as a guide for future geolinguistic researchers who, like us, will be willing to leave the comfort of their homes and venture through the extraordinary universe of language spoken in everyday life. In order to scientifically base our work, we refer to Caruso (1998), Brandão (2005), Alencar et al. (2016), Ferreira (2016).
\end{abstract}

Keywords: Dialetology. Methodology. Geolinguistics. Ceará. 


\section{INTRODUÇÃO}

Este artigo tem por objetivo relatar os desafios enfrentados na pesquisa geolinguística durante fase de pesquisa de campo do Atlas Linguístico dos Sertões Cearenses (doravante ALSCe). Esse atlas linguístico documentará o léxico e a morfossintaxe do falar cearense na mesorregião geograficamente definida como os Sertões Cearenses e se constitui como a tese de doutorado em Linguística da Universidade Federal do Ceará da pesquisadora Fabiana Lima.

Para a produção de um atlas linguístico, é necessário, antes de ir a campo, um planejamento minucioso e rigoroso. Há que se considerar e definir as variáveis extralinguísticas, como local, sexo, idade e escolaridade. Desse modo, traçamos neste artigo um relato da pesquisa de campo para a produção do ALSCe, de modo que este sirva como orientação a futuros pesquisadores geolinguísticos que estejam dispostos a desenvolver esse tipo de pesquisa. Esse é um trabalho que exige do pesquisador a saída do seu ambiente de estudo, para imergir no contexto da língua falada em sua situação concreta de uso.

Mesmo com um projeto bem estruturado, com a metodologia minuciosamente planejada e previamente definida, quando vamos a campo, precisamos lidar com inúmeros desafios que, certamente, não havíamos previsto durante o projeto. Nesse caso, é preciso que o pesquisador tenha a capacidade de lidar com os desafios, no sentido de superá-los e usá-los a seu favor.

Como referencial teórico, adotamos as contribuições de Caruso (1998), Brandão (2005), Alencar et al. (2016), Ferreira (2016). Todos esses autores traçam diretrizes metodológicas sobre a pesquisa geolinguística, que envolve também a dialetologia e a sociolinguística.

Este artigo tem a seguinte organização: primeiramente, traçamos a fundamentação teóricometodológica que norteia nossa pesquisa e, por fim, relatamos os percursos metodológicos vivenciados durante a fase de pesquisa de campo para a concretização do ALSCe.

\section{FUNDAMENTAÇÃO TEÓRICO - METODO- LÓGICA}

Partindo da discussão sobre o paradoxo do pesquisador acerca do método empírico a ser utilizado, ter um procedimento teórico-metodológico é de extrema importância para a sustentabilidade e o reconhecimento de uma pesquisa, como podemos encontrar nos questionários do projeto ALIB (2013). Desta forma, o método geolinguístico é um importante instrumento de pesquisa que vem alicerçando as pesquisas dialetológicas, realizadas por estudiosos do Brasil como um todo. Foi graças ao rigor em sua aplicação que se conseguiu realizar o sonho de se produzir o ALIB (Atlas Linguístico do Brasil), um projeto audacioso que envolveu centenas de pessoas e viajou o Brasil do Oiapoque ao Chuí em busca de documentar fala brasileira.

Sendo assim, todo atlas linguístico brasileiro produzido desde a implantação do Projeto ALIB segue o mesmo princípio metodológico, unindo dialetologia, geolinguística e sociolinguística, para que seu resultado seja um conjunto de informações relevantes tanto para a comunidade acadêmica quanto para a sociedade como um todo.

Desta forma, os elementos metodológicos para se realizar uma pesquisa geolinguística e, consequentemente, produzir um atlas linguístico são: escolha da localidade e dos informantes, pesquisa de campo, transcrição grafemática e/ou fonética, arquivamento dos dados, seleção dos dados e produção das cartas linguísticas.

É seguindo esta metodologia que nasce o ALSCe (Atlas Linguístico dos Sertões Cearenses), tese de doutoramento da pesquisadora Fabiana Lima, que já produziu o ALIg (Atlas Linguístico Léxico-semântico de Iguatu) e vem dando continuidade às pesquisas geolinguísticas no estado do Ceará.

Dessa vez, a região escolhida foi a mesorregião dos Sertões Cearenses, primeiramente, por se localizar a cidade de Quixadá, local de residência e de trabalho da pesquisadora, depois por ser a maior mesorregião do estado e, por fim, por ela ser dividida em 04 microrregiões que se assemelham em clima e relevo, contendo ao todo 30 cidades.

Sendo assim, escolhemos duas cidades para representar cada microrregião e uma cidade que representasse o centro da mesorregião, perfazendo uma malha linguística de 09 cidades a serem pesquisadas. Na tabela 01 apresentada a seguir, apresentamos as quatro microrregiões e suas respectivas cidades selecionadas para realizarmos os inquéritos.

Feita a escolha das cidades onde se realizará os inquéritos, conforme exposto na Tabela 01, outro passo bastante importante antes da pesquisa de campo é a seleção dos informantes. O critério de escolha segue as orientações do projeto ALIB, em que se destacam as variações diageracional, diassexual e diafásica, ou seja, os informantes são selecionados segundo a idade, sexo e escolaridade. Diante disso, para cada localidade deveríamos escolher um homem e uma mulher que estivesse dentro de 02 faixas etárias (18-30 e 45-60) com 
Tabela 1: Microrregiões e pontos de inquéritos

\begin{tabular}{cc}
\hline Microrregiões & Pontos de Inquéritos \\
\hline Sertão de Crateús & Crateús e Nova Russas \\
Sertão de Inhamuns & Aiuaba e Tauá \\
Sertão de Quixeramobim & Boa Viagem e Quixadá \\
Sertão de Senador Pompeu & Acopiara, Milhã e Pedra Branca \\
\hline
\end{tabular}

grau de escolaridade até, no máximo, o $9^{\circ}$ ano do Ensino Fundamental II. Contudo, mesmo em se tratando de cidades do interior, fizemos um adendo ao perfil escolar, aumentando o primeiro grau até o ensino médio e escolhendo também informantes que tivessem nível superior, devido ao elevado número de instituições de nível superior que há na região.

Vejamos o que orienta os documentos do ALIB (2013):

Quanto à escolaridade, entende-se que o tipo de informante representativo de cada localidade não deve estar nos graus extremos de formação, optando-se por indivíduos alfabetizados e que tenham cursado, no máximo, até a $4^{\mathrm{a}}$ série 1 Excetuam-se as capitais de estado, onde, levando em conta a maior densidade e a grande diversidade de estratos sociais, o número de informantes é maior, incluindo-se também quatro informantes de níve de escolarização universitário. (ALIB, 2013, pp. 39-40).

Com essa mudança na variável escolaridade, o número final de informantes por ponto ficou fixado em 08, perfazendo um total de 72 informantes a serem inquiridos, assim distribuídos: 18 mulheres e 18 homens com faixa etária entre 18 e 30 , subdivididos em 09 de até nível médio e 09 de nível superior, e 18 mulheres e 18 homens com faixa etária entre 45 e 60, também subdivididos em 09 de até nível médio e 09 de nível superior. Após essas definições, era preciso decidir o que seria pesquisado e quais questionários seriam aplicados, já que o projeto ALIB trabalhou com 03 questionários: o Questionário Fonético-Fonológico (doravante QFF), o Questionário Semântico-Lexical (doravante QSL) e o Questionário Morfossintático (doravante QMS), além de questões de prosódia, pragmática, metalinguística e discursos semidirigidos com a intenção de "alcançar um nível de adequação e propriedade compatíveis com as necessidades de um projeto como este, de âmbito nacional." (CARDOSO et al. 2013, p. 41)

Sendo assim, com o intuito de registrar o léxico e as expressões morfossintáticas desse espaço geográfico, optamos por aplicar apenas o QSL e o QMS. É bem verdade que todo geolinguista tem uma predileção pelo léxico, como confessa Ferreira (2016):

\footnotetext{
${ }^{1} \mathrm{Em}$ função das dificuldades apresentadas durante a pesquisa de campo, exigiu-se a ampliação da escolaridade até a $8^{\mathrm{a}}$ série.
}

Tudo que a Geolinguística nos mostra e ensina é igualmente importante, mas temos um gosto especial pelo estudo do léxico, por isso a nossa preferência pelas cartas semânticolexicais. Não é apenas pela visão diacrônica mais imediata que elas possibilitam, e sim porque nos fazem chegar mais próximo ao mundo do informante e da cultura local, lato sensu. O estudo do léxico amplia o nosso interesse, aguça a nossa curiosidade, exercita nosso raciocínio (FERREIRA, 2016, p. 15).

Feito isso, selecionamos as fichas da localidade e do informante necessárias à constituição do perfil tanto da localidade quanto do informante, bem como as realias ${ }^{2}$ que auxiliam em algumas perguntas do questionário semântico-lexical e o material de gravação ${ }^{3}$ Esquematizamos, no quadro 01, os critérios de escolha dos informantes e as fichas e questionários que compõem o material utilizado na coleta de dados, a fim de facilitar o entendimento do pesquisador iniciante nesse tipo de pesquisa.

Como vimos no quadro 01, realizar um trabalho dessa proporção não é uma tarefa simples. Foi necessário montar uma equipe de trabalho para que tudo o que foi projetado seja cumprido. Essa equipe foi parcialmente constituída por meios de aprovação de projetos de pesquisa pelo Conselho Nacional de Desenvolvimento Científico e Tecnológico (CNPq) e pela Fundação Cearense de Apoio ao Desenvolvimento Científico e Tecnológico (FUNCAP), proporcionando a seleção de 03 bolsistas PIBIC e PIBIC Jr.

A simplicidade com que abordamos os passos preparatórios da pesquisa geolinguística não atesta a complexidade de todo o processo que pode levar ao sucesso ou desistência da empreitada. É nesse viés que iremos detalhar os caminhos trilhados por essa pesquisa de campo e toda a sua dinâmica em busca de dados genuínos da mesorregião Sertões Cearenses do Estado do

\footnotetext{
${ }^{2}$ Representação gráfica de determinado vocábulo, como flash card.

${ }^{3}$ Gravador digital de voz da marca ZOOM H4NSP, com cartão de memória de 8 gigabites à pilha.
} 
CAMINHOS PERCORRIDOS PELA GEOLINGUÍSTICA NOS SERTÕES CEARENSES: PESQUISA DE CAMPO

Tabela 2: Critério de escolha dos informantes e material usado na coleta de dados

\begin{tabular}{|c|c|c|}
\hline \multicolumn{2}{|r|}{ Informantes } & Questionários \\
\hline Quantidade & 72 & Ficha da Localidade \\
\hline Faixa etária & $\begin{array}{l}\text { I - } 18 \text { a } 30 \text { anos } \\
\text { II }-45 \text { a } 60 \text { anos }\end{array}$ & Ficha dos Informantes \\
\hline Sexo & $\begin{array}{l}\text { Homens - } 36 \\
\text { Mulheres - } 36\end{array}$ & $\begin{array}{c}\text { Questionário Semântico-Lexical (QSL), } \\
\text { com } 202 \text { perguntas que recobrem } \\
15 \text { áreas semânticas; }\end{array}$ \\
\hline Escolaridade & $\begin{array}{l}\text { 1. Alfabetizado até o Ensino Médio } \\
\text { 2. Ensino Superior }\end{array}$ & $\begin{array}{l}\text { Questionário Morfossintático (QMF), } \\
\text { com } 49 \text { perguntas morfossintáticas }\end{array}$ \\
\hline
\end{tabular}

Ceará.

Com toda a fundamentação teórica e o material devidamente selecionado e preparado, vamos à campo.

\section{RELATO DOS CAMINHOS PERCORRIDOS PELA GEOLINGUÍSTICA NO ALSCE}

Neste capítulo, detalhamos o percurso realizado durante a pesquisa de campo para a coleta de dados necessários para a concretização do ALSCe.

\subsection{A coleta}

Foi com ousadia e certa imprevisibilidade que iniciamos nossa jornada. Começamos nosso trabalho pela cidade de Quixadá, por se tratar de nossa espécie de "porto seguro" e de certa forma para experienciar os desafios que viriam a seguir. $\mathrm{O}$ maior deles foi e sempre será conseguir o informante ideal. Nessas ocasiões da pesquisa de campo, Ferreira cita as palavras do mestre Nelson Rossi: "há apenas $25 \%$ de previsão, os outros 75\% são imprevisíveis" (FERREIRA, 2016, p. 18).

Ao se referir à habilidade com que os inquiridores conseguem extrair as respostas desejadas dos informantes, Caruso (1998) também parece entender essa etapa da pesquisa de modo similar, quando defende ser "por isso que se diz que toda pesquisa de campo é um 'voo cego', mesmo estando treinadíssimos, é possível se defrontar-se com situações jamais imaginadas." (CARUSO, 1998, p. 194).

O segundo maior desafio foi definir o local do inquérito, pois deveria ser um ambiente onde a gravação ficasse audível e, ao mesmo tempo, transmitisse segurança e espontaneidade ao informante. Sendo assim, demos preferência à residência ou local de trabalho. Contudo, nem sempre foi possível que a coleta ocorresse nesses lugares, acontecendo também em ambiente inusitados, como quarto de hotel, depósito de academia, loja de confecção, bodega e recepção do museu da cidade.
Os passos geralmente seguidos para realizar os inquéritos em cada localidade são o contato com pessoas da prefeitura e/ou instituições de ensino, para explicar o objetivo da pesquisa e obter ajuda para encontrar pessoas que se adequem aos perfis préestabelecidos. No entanto, a melhor estratégia utilizada foi encontrar uma pessoa influente em cada localidade que conhecesse muita gente e que tivesse a credibilidade para convencer o informante a participar da coleta de dados.

Essa estratégia foi percebida ao chegarmos na cidade de Acopiara. Após passarmos o dia rua acima, rua abaixo em busca de informantes, a terceira informante do dia, por conhecer nosso irmão que nos acompanhava, propôs-se a conseguir os demais informantes. Desse modo, no dia seguinte, foram realizadas as demais entrevistas com sua providencial ajuda. Desde então, nosso intuito era encontrar uma pessoa influente nas cidades seguintes. Nem sempre isso ocorria com tanta facilidade, mas ao encontrá-la, o desenrolar dos inquéritos eram muito mais fluidos.

Não nos restam dúvidas de que o ideal é que, além do inquiridor, outras pessoas o auxiliem na aplicação dos questionários; contudo, devido à dificuldade de locomoção, os inquéritos do ALSCe foram aplicados somente pela pesquisadora, com exceção da cidade de Quixadá, onde obtivera auxílio de sua equipe de bolsistas.

Com isso, passávamos geralmente 03 dias em cada localidade. O primeiro dia se destinava à identificação do informante e agendamento do horário adequado para cada um. Nos dois dias seguintes, realizávamos as entrevistas, que duravam em torno de uma hora e meia entre aplicação da ficha do informante e a realização dos inquéritos. Somente dois inquéritos foram parcelados, ou seja, o QSL aplicado num dia e o QMS no outro. Isso aconteceu nas cidades de Quixadá e de Boa Viagem, por conta do excesso de informações repassadas 
pelos informantes 4 que acabou extrapolando o próprio tempo deles e tivemos que remarcar para o dia seguinte.

Apesar de o tempo de estada em cada localidade ser apenas 03 dias, o tempo necessário para concluir todos os inquéritos foi de 05 meses. Entre idas e vindas, foram quase dois mil quilômetros de estradas rodadas, inclusive de terra. Acreditamos que as serras de Pedra Branca ficaram amigas íntimas do nosso automóvel.

Quando lemos as "Histórias e memórias do projeto ALIB" (2016), identificamo-nos com algumas delas e fomos, inclusive, personagem em uma. Quando Ferreira (2016, p. 18) diz que "Deus foi eleito dialetólogo" e que "uma coorte de anjos também compareceu nessas viagens, alguns até corporificados", recordamo-nos da coleta de dados em Aiuaba.

Depois de um feriado da Semana Santa, estávamos em Iguatu, com todos os preparativos necessários para ir a Aiuaba, mas não sabíamos nem como chegar lá. Recorremos, então, ao Sistema de Posicionamento Global, mais conhecido pela sigla GPS. Este nos indicava que o trajeto mais rápido era por Saboeiro. Assim, seguimos para tão longínqua localidade.

Quando chegamos a Saboeiro, como não conseguíamos nos entender com o GPS, apelamos para um cidadão que notou nosso desespero e nos indicou o caminho certo. Ao chegar na direção indicada, deparamo-nos com um rio bem cheio, pois era o período de inverno. Perguntamos: “tem certeza?", e o cidadão: "num é pra Aiuaba? É só atravessar o rio e seguir em frente.” E nos perguntávamos: "cadê a pista? Bem, ela deve estar logo à frente." Ledo engano. Foram 27 quilômetros de estrada carroçável, mata fechada, poças de lama, grotas e pedras, Deus e todos os anjos dos céus, tamanho foi o nosso desespero naquela situação. Um verdadeiro rally off-road 5 .

Felizmente nosso objetivo foi alcançado. Após 03 dias de trabalho, pudemos voltar à nossa residência pela rodovia estadual com os inquéritos devidamente realizados e com um saldo do vidro dianteiro do carro quebrado, duas rodas empenadas e muita história para contar.

Ainda sobre as "Histórias e memórias do projeto ALIB”, Alencar et al. (2016) relata sobre uma saia justa em que se encontrou diante de uma informante que possuía todo o perfil de um informante ideal, mas possuía uma falha: a falta de dentes na parte superior da boca, impedindo a realização de alguns sons fonéticos. Este

\footnotetext{
${ }^{4}$ Em Quixadá - mulher, $2^{\text {a }}$ faixa etária, nível superior. Em Boa viagem - homem, $2^{\mathrm{a}}$ faixa etária, nível superior.

${ }^{5}$ Competição automobilística realizada fora da estrada de rodagem.
}

fato nos fez recordar de uma situação semelhante que nos ocorreu em Pedra Branca. Nosso ajudante havia contactado o informante sem confirmar a idade e o lugar de nascimento. Quando fomos preencher a ficha do informante, percebemos que o senhor estava fora do perfil nas duas variáveis. Contudo não conseguimos nos desvencilhar e todo o inquérito foi aplicado. Tempos depois tivemos que voltar à localidade para buscar um novo informante e realizar o inquérito adequadamente.

Fato semelhante ocorreu em Boa Viagem. A informante mulher de $1^{\mathrm{a}}$ faixa etária e até nível médio não era natural da localidade. Foi mais um inquérito que teve de ser refeito. Diante desses dois fatos, a verificação exata do perfil do informante antes da abordagem passou a ser mais cuidadosa.

Algo que é de extrema importância para um pesquisador de campo é o instrumento de gravação. Dependendo da escolha desse instrumento, podemos ter grandes prejuízos. Imaginemos todo o trabalho que tivemos durante a coleta de dados e, ao ouvir a gravação, detectar que não gravamos ou que não está audível.

Devido a vários problemas que tivemos na coleta do ALIg, reforçamos nossa atenção nesse elemento. Dessa forma, escolhemos um gravador digital de voz da marca ZOOM H4NSP, com cartão de memória de 8 gigabites à pilha devidamente orientada. Com essa escolha, tínhamos dois objetivos: primeiro, ter um instrumento de qualidade e de fácil manuseio durante os inquéritos, proporcionando uma excelente captação do som; segundo, fazer a gravação em formato wave para que pudéssemos futuramente estudar alguns sons fonéticos por meio de um programa de fonética acústica chamado Praat.

Mesmo com todo esse cuidado, imprevistos acontecem. E problemas de gravação são os mais citados nas histórias e memórias do ALIB. Quase nenhum pesquisador escapa dessas "saias justas”. Alencar (2016), referindo-se à coleta dos pontos do Ceará, cita vários. Dentre eles, ter que refazer os inquéritos na mesma hora. Levando-se em consideração que uma coleta do ALIB gira em torno de duas horas e trinta minutos, foram necessárias cerca de 5 horas para cada um.

Na nossa coleta também tivemos dois fatos que envolveram dificuldades com a coleta de dados. O primeiro ocorreu em Quixadá. Após temos realizado toda as coletas, partimos para o segundo ponto em Acopiara e todas as entrevistas estavam no cartão de memória, mesmo tendo passado todas as entrevistas para um arquivo no computador. No entanto, a última entrevista de Quixadá não havia sido repassada para o computador e, por necessidade de espaço no cartão de memória, 
ela foi apagada. Só percebemos o equívoco após conferir todas elas. Nesse momento, só temos uma palavra para definir a situação: desespero.

Uma dúvida cruel se instalou no íntimo da pesquisadora. Explicar o acontecido ao informante e solicitar uma nova coleta ou buscar um novo informante com o mesmo perfil. A pesquisadora, tempos depois, optou pela primeira opção e refez a pesquisa.

O segundo fato aconteceu em Crateús com o informante homem, $2^{\mathrm{a}}$ faixa etária nível médio. Pelos nossos cálculos, a bateria do gravador era suficiente para fazer mais uma coleta. Contudo, o contexto do inquérito não se apresentou nada favorável. Aconteceu em uma bodega bastante movimentada em que a gravação tinha que ser parada gradativamente. Além das paradas, ainda tínhamos um informante que se apresentou tímido, mas que, com o desenrolar da conversa, mostrouse bastante acessível. Poderíamos dizer que "conversou mais do que o homem da cobra", ditado popular. Com isso, a bateria acabou e não tínhamos ideia de qual momento da entrevista havia falhado. Felizmente o estabelecimento era próximo ao local de nossa hospedagem. Imediatamente pegamos o notebook e verificamos onde a gravação havia parado e demos sequência ao inquérito. Relevando esses percalços, ao depararmonos frente à frente com o informante, um universo se abre diante de nós. Tudo é possível quando a alma não é pequena, já dizia o poeta. E, como se fôssemos amigos de longa data, fatos de pura intimidade são descortinados naturalmente. É nesse momento que percebemos toda a grandeza de uma pesquisa de campo.

Neste contexto, 03 casos ficaram gravados em nossa memória. O primeiro ocorreu em Quixadá, ao realizarmos a pergunta 36 do QSL à informante de $1^{\mathrm{a}}$ faixa etária, nível médio: "Hoje é segunda-feira. E domingo, que dia foi?" INF. 02/01: “dia de fazer sexo!". Foi difícil conter o riso, mas mantivemos a compostura.

O segundo caso ocorreu quando estávamos em Milhã, inquirindo o informante homem de $2^{\mathrm{a}}$ faixa etária, nível superior. Ao realizarmos a pergunta 44 do QSM (O que você faria se ganhasse na loteria?), o informante disse que a pergunta tinha sido boa e daí começou a fazer um desabafo explicando o que ele achava de ganhar muito dinheiro. Enquanto ele falava, nós pensávamos: "nós só estamos em busca de uma forma verbal e damos a oportunidade de alguém desabafar". Vejamos alguns trechos da conversa.

Pra começo de história eu não gosto de dinheiro, (pra você ver como foi boa essa pergunta) dinheiro pra mim, a gente precisa de dinheiro pra ter uma vida digna, uma vida digna, ter e dar a família, educação, principalmente educação e saúde, (...). Eu prefiro não ter. Resumindo a história, pode até alguém achar que sô doido, mah heu num gosto de riqueza, eu num gosto, eu num tem ambição, (...) Mas eu faria isso com certeza se ganhasse na loteria. Eu nem quero ganhar, aquilo ali é um desassossego de vida. Você acostumado com pouco dinheiro, de repente você se vê com muito dinheiro. É um perigo de vida, éé ser sequestrado[...]. (INF. 07/07 - ALSCE, 2017).

Já o terceiro caso aconteceu em Crateús com o dito informante com quem a bateria acabou. Durante a aplicação do QSL, na tentativa de obter as respostas para os itens lexicais inquiridos, ele nos confidenciou que, além dos filhos com sua esposa, tinha mais um filho fora do casamento e que se encontrava bastante arrependido de ter cometido a traição, no entanto tinha todo o prazer de ter tido mais um filho.

Situações contrárias a essas também podem ocorrer especialmente quando o informante percebe o pesquisador como "um elemento estranho, um desconhecido, munido de gravador, lápis e papel, falando uma língua diferente da sua." (CARUSO, 1998, p. 191). Identificamos essas situações especialmente entre os informantes de $2^{\mathrm{a}}$ faixa etária que possuíam um nível de escolaridade muito baixo. Enquanto esperávamos coletar dados bem genuínos, deparávamos simplesmente com a resposta Não Sei, mediante a vergonha que sentiam por acharem que estavam em frente a uma "dôtora". Nesses casos, era preciso muita habilidade do inquiridor para quebrar essa barreira e alcançar o objetivo pretendido.

Não podemos negar o prazer do pesquisador em realizar seu trabalho. No entanto, momentos de frustração e desânimo também são latentes. Nem sempre as portas se encontram abertas ao geolinguista. Duas ocorrências de constrangimento e frustração abateram nosso destemido espírito pesquisador, mas que foram superadas prontamente.

A primeira foi em Boa Viagem. Tínhamos acabado de chegar e não tínhamos nenhum contato inicial. O jeito seria buscar a Secretaria de Assistência Social da cidade para nos encaminhar a algum lugar e a alguém. Nessas indicações, devido ao horário, fomos enviados a uma escola de ensino médio noturna. Chegando lá, deparamo-nos com uma diretora nada simpática, mas mesmo assim disposta a nos ajudar. Então, pediu para chamar um dos alunos dentro do perfil indicado para marcarmos a entrevista. $\mathrm{O}$ fato foi que o informante sugeriu que fizéssemos a entrevista ali mesmo e nós, empolgadas e sem o consentimento prévio da dita diretora, iniciamos o inquérito. Isso a deixou bastante irritada e nós numa situação de extremo constrangimento com direito a mil pedidos de desculpas, sem nenhuma chance de ser desculpadas. Pelo menos, valeu à pena. Nos dias 
seguintes, Deus nos enviou um anjo em forma de informante e persona grata para nos conduzir nas demais entrevistas.

A segunda ocorreu em Crateús. Já vínhamos de Nova Russas, o cansaço já estava batendo à porta, mesmo assim ainda estávamos motivadas. Fomos visitar mais uma escola de ensino médio noturna. Quando passávamos os perfis para o simpático coordenador pedagógico, a diretora geral chega e pergunta do que se trata; pacientemente explicamos e, ao final, da nossa explicação, ela diz que só seria possível nos ajudar com uma carta de recomendação. Neste momento, a energia restante se esvaiu. Educadamente agradecemos a atenção e retiramo-nos. Como era uma quinta-feira à noite e no dia seguinte era um dia de paralização nacional, não tivemos outro jeito a não ser voltar para casa.

Um mês depois voltamos e realizamos todos os inquéritos sem a necessidade de carta de recomendação e auxiliada por uma coordenadora de cursos de pósgraduação e muito influente na cidade. Com isso, finalizamos toda a coleta de dados a que nos propomos.

\section{CONSIDERAÇÕES FINAIS}

Não é à toa que Brandão (2005, pp. 363-4) relata que "a pesquisa na área das Ciências Humanas é um ato político devido aos vínculos que se estabelecem com os indivíduos que fornecem os corpora". Em se tratando do ALSCe, esses vínculos foram feitos com cada indivíduo que contribuiu para a construção desse trabalho. Se trazemos um pouco deles, também deixamos um pouco de nós, numa tessitura como o galo que constrói cada manhã.

A lição de vida que recebemos de cada informante é inegável. Relatamos aqui apenas alguns fatos, mas podemos afirmar que, em cada inquérito, se desabrochava em nossa frente um ser magnífico e deslumbrante simplesmente para nos ajudar. São experiências que transformaram nosso viver e que, assim, poderíamos repetir as palavras de Cintra, muito bem referenciadas por Brandão (2005, p. 369), que simplesmente sintetizam a nossa percepção neste momento da pesquisa: "Se mais nada, no vasto terreno da linguística, conservasse um dia interesse para mim, creio que esta experiencia seria só por si suficiente para me obrigar a reconhecer e afirmar que vale a pena o ramo de estudos para que a vida me conduziu."

É diante de experiências como essas que acreditamos na importância da língua para a construção sociocultural de uma comunidade linguística.

por meio da língua, o homem recria a realidade, interpretando-a e repassando-a aos demais. Aprisionado às suas estruturas, obediente às regras que lhe garantem a intercomunicação, preserva formas tradicionais; sensível às modificações que operam a sua volta, nela imprime suas marcas, renovando-a cada apelo externo. (BRANDÃO, 2005, p. 364).

Exemplo disso é descobrir a origem de uma expressão popular tão corriqueira em nosso cotidiano; mas, quando questionada, obtemos uma resposta padrão. Trata-se da pergunta 121 do QSL (As mulheres perdem sangue todos os meses. Como se chama isso?). Geralmente a resposta é menstruação, contudo é muito comum em nossa região a expressão "tá de bode".

Em conversas sobre expressões populares, nosso ajudante de Boa Viagem nos explicou que a origem dessa expressão era o fato das mulheres, no passado, terem dificuldades de se assearem e, quando estavam no período menstrual, se cobriam com folhas de bananeiras. Então, a falta de higiene, a regra e a folha da bananeira causavam um odor imenso, semelhante à urina do bode no chiqueiro. Daí a origem da expressão.

Esse relato vai muito mais além do que a explanação de experiência do pesquisador no campo de atuação, reconstrói a história de um povo, de uma localidade, de uma geração e, ao mesmo tempo, traz elementos de inovação, constituindo o caráter dinâmico que uma língua possui.

É nesse aspecto que discorremos ao longo deste trabalho, para servir de orientação para futuros pesquisadores geolinguistas que, assim como nós, estarão dispostos a deixar o conforto de seus lares e se aventurarem pelo universo extraordinário da língua falada no cotidiano.

\section{REFERÊNCIAS}

ALENCAR, M. S. M. d.; PONTES, A. L.; ARAúJO, A. A. d.; MONTEIRO, J. D. S. Aconteceu de tudo no alib do ceará. In: CARDOSO, S. A. M.; MOTA, J. A.; PAIM, M. M. T.; RIBEIRO, S. S. C. (Ed.). Documentos 6: histórias e memórias. Salvador: Quarteto, 2016. p. 77-85.

BRANDãO, S. F. A história e as contribuições de um projeto na linha geolinguística. In: AGUILERA, V. d. A. (Ed.). A Geolinguística no Brasil: trilhas seguidas, caminhos a percorrer. Londrina: UEL, 2005. p. 355-370.

CARDOSO, S. A. M.; MOTA, J. A.; PAIM, M. M. T.; RIBEIRO, S. S. C. Projeto Atlas Linguístico do Brasil: documentos 4. 1. ed. Salvador: Vento Leste, 2013. 
CARUSO, P. Metodologia da pesquisa dialetológica. In: AGUILERA, V. d. A. (Ed.). A Geolinguística no Brasil: caminhos e perspectivas. Londrina: UEL, 1998. p. 189-195.

FERREIRA, C. d. S. Uma palavra à guisa de apresentação. In: CARDOSO, S. A. M.; MOTA, J. A.; PAIM, M. M. T.; RIBEIRO, S. S. C. (Ed.). Documentos 6: histórias e memórias. Salvador: Quarteto, 2016. p. 13-21. 